\title{
A propósito da ética, da Psicologia e da Psicanálise
}

\author{
Sérgio Laia * \\ (*) Graduado em Psicologia, mestrando em \\ Filosofia pela Universidade Federal de Minas \\ Gerais (UFMG). Psicanalista, membro do \\ Simpósio do Campo Freudiano. Professor de \\ Psicologia Social na Faculdade de Ciências \\ Humanas - Fundação Mineira de Educação e \\ Cultura (FCH-FUMEC)
}

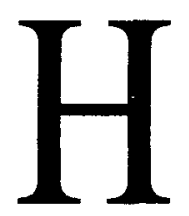

á uma pequena passagem de um texto de Lacan intitulado Kant avec Sade que é o ponto de partida deste meu trabalho. Situando a alcova (boudoir) sadeana em relação às escolas de filosofia grega (Academia platônica, Liceu aristotélico, Escola dos estóicos), Lacan escreve que nesses lugares "prepara-se a ciência retificando a posição da ética"(1): a elaboração da ciência se articula, então, a retificações no que concerce à ciência do ethos. Trata-se de uma leitura instigante a propósito da ética.

$\mathrm{Na}$ Grécia do século IV a.C., período no qual se localizam as escolas que Lacan cita em Kant avec Sade, a reflexão sobre a ética torna-se possível, sob perspectivas diferentes em cada uma dessas escolas, a partir daanalogia ethos/ physis. É importante salientarmos que se trata de uma relação ANALÓGICA, onde um termo não se confunde de modo algum com o outro pois pertencem a campos diferentes da Filosofia. É que em grego o ethos ( $\ddot{\varepsilon} \theta 0 \zeta$ ), enquanto costume, caráter é também morada ( $\ddot{\varepsilon} \theta 0 \zeta$ ) que abriga o homem diante da dureza da necessidade (ananké) e da instabilidade da natureza (physis). O ethos eleva-se, então, sobre a physis, pois enquanto esta se caracteriza pelo que é sempre (tou aei), ele implica o advento do dife- rente, do particular, do que deve ser, pois se inscreve "no espaço da liberdade aberto pela praxis", o ethos é o que é "muitas vezes" (tou pollákis) (2) - nesse contexto, parece não haver analogia alguma entre ethos e physis. No entanto, ethos é também hábito ( resulta da repetição constante dos mesmos atos sem, contudo, ocorrer sempre ou ter uma necessidade natural e que, ao atingir sua forma acabada, torna-se possessão estável (héxis), "princípio próximo de uma ação posta sob o senhorio do agente e que exprime a sua autarquéia, o seu domínio de si mesmo" (3). Nesse último viés, o ethos como hábito acaba por recriar algo da permanência e da continuidade que caracteriza a physis enquanto ordem universal que serve, entre os gregos, de fundamento de uma lei (nomos) a qual a praxis e o agir humanos podem se referir.

Como nos mostram Jaeger ${ }^{(4)}$ e Lima $\mathrm{Vaz}^{(5)}$, é ao firmar-se nesta relação analógica que o mundo grego conseguirá fazer frente ao duro golpe sofrido pela queda brusca de Atenas e de tudo que esta Cidade-Estado significou, sob 0 império glorioso de Péricles, para o mundo helênico. Jaeger escreve que a derrocada ateniense "deixava nos limites do Estado grego um vazio difícil de preencher" (6), pois até então a cultura grega fora sempre inseparável da vida

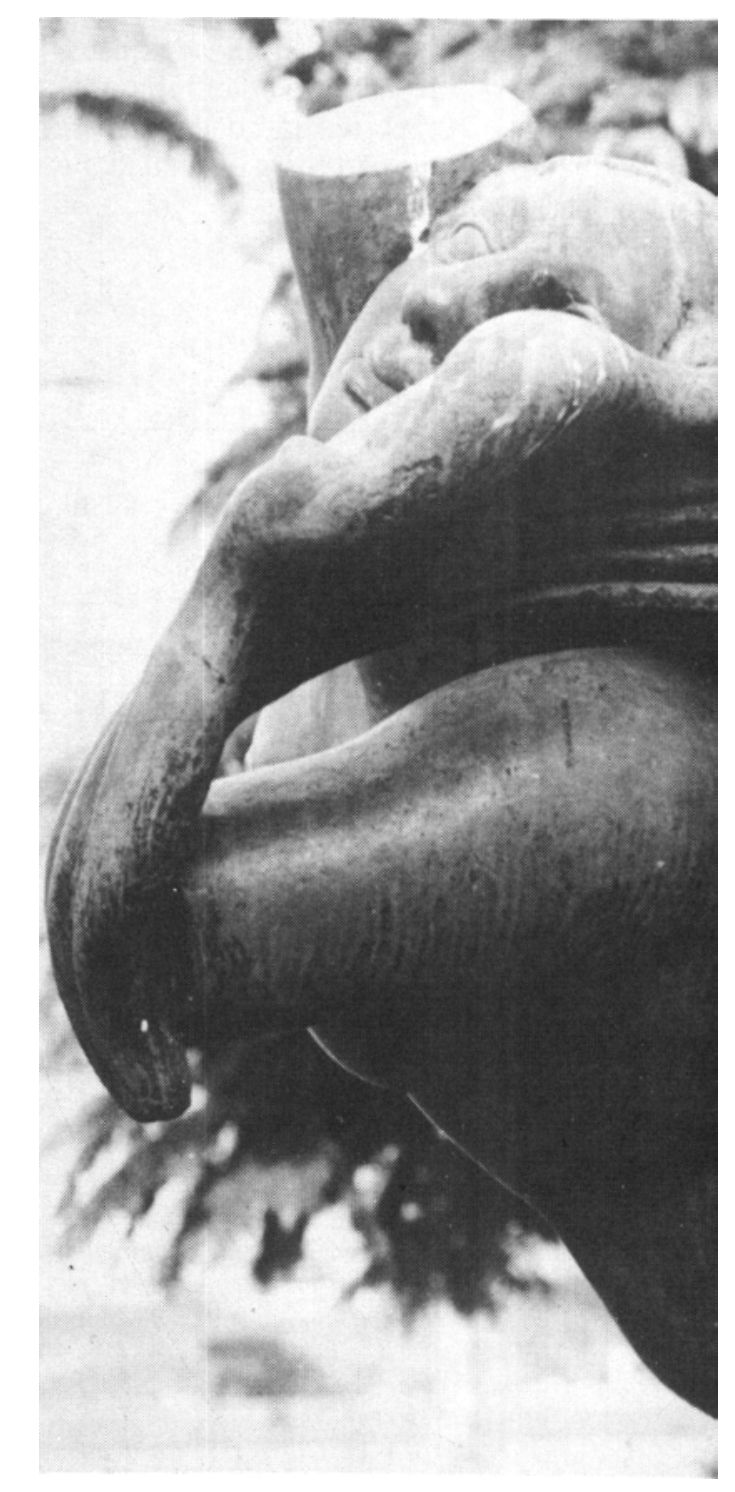






do Estado, da Cidade enquanto polis, especialmente em Atenas. Assim, este acontecimento repercutiu sobre a vida política, moral e religiosa dos gregos e "é destes tempos dolorosos que parte a volta para a interioridade que o espírito grego faz nos séculos seguintes "(7). Por isso podemos conceber as escolas de filosofia que se desenvolveram no século IV a.C. como uma resposta a este vazio deixado pela derrocada de Atenas ao fim de uma guerra que, por 30 anos aproximadamente, agitou os Estados gregos. A analogia ethos/physis sustenta, então, esse desafio do mundo grego de pensar o campo ético SEGUNDO a ordem da natureza (segundo o kosmos), após a perda dessa referência fundante que era a polis. É bem isso que podemos captar na bela citação que Aristóteles nos faz de Eveno: “(...) o hábito é uma longa preparação, meu amigo e a preparação, enfim, torna-se para o homem uma natureza" (8).

$O$ curioso - e o que difere radicalmente o mundo grego clássico do nosso - é que, embora longa e permanente, tal preparação era dirigida apenas aos varões gregos que desfrutavam do ócio e da liberdade. Ela servia então como uma espécie de orientação que, lhes assegurando o domínio e o cuidado de si, lhes possibilitava o governo dos outros ${ }^{(9)}$. Por isso, não encontramos entre os gregos codificações de condutas, de deveres ou de ordem. A reflexãoética que eles produziram, ensina Brochard, nos apresenta opções, manuais de conselhos, receitas de modelos a serem seguidos porque as leis para eles tomam muito mais a forma de costumes e convenções do que de imperativos e obrigações ${ }^{(10)}$. O que se estabelece, pois, no século IV a.C., sob perspectivas bem diferentes em cada uma das escolas que aí surigram, são concepções éticas aristocráticas, onde a figura e a função do senhor ocupam uma posição fundamental. Por mais que a noção que temos habitualmente da ética ainda implique concep̧̧̃es como "ser senhor de sî" , "ser honrado", "ser livre", "estar submetido às leis" etc., não podemos dizer que damos ao termo SENHOR (e mesmo ao termo ÉTICA, como veremos) exatamente as mesmas significações que os gregos lhes davam.

No que concerne mais especificamente ao termo SENHOR e à função de DOMÍNIO, nossa distância em relação aos gregos se explicita, por exemplo, na 
Idade Média, quandoos usurários (aqueles que querem fazer o dinheiro gerar dinheiro a partir dele mesmo) surgem como os precursores de um sistema econômico onde a posição do senhor vai ser sustentada exclusivamente pelos homens de negócio, istoé, pelos homens que negam oócio. Énomundo medieval que, tornando-se "mãe de todos os vícios"(11), a ociosidade perde o valor que tinha para os gregos até se desfigurar, nos nossos dias, nessa atividade ao mesmo tempo tão almejada, explorada, insossa e previsível que é o lazer com o qual tanto os senhores modernos, como seus funcionários, podem se comprazer nos fins de semana e nas férias anuais para se refazerem dessas exaustivas atividades que lhes permitem - não sem tensões - o domínio de si, dos outros e a liberdade. Assim, cada vez mais, a vida passa a ser para nós muito mais um meio (de salvar a alma, de enriquecer, de ser feliz, de ser livre...) do que - como ocorria entre os gregos - um fim nela mesmo.

É curioso notar que a própria noção de NATUREZA não tem para nós o mesmo valor que ela possuía na Grécia. Na modernidade, a natureza já não é mais apreendida como a physis imutável em sua ordem e fundamento de uma lei (nomos) objetiva que dava ao instável agir humano uma referência. Na modemidade, Galileu demonstra que a natureza está inscrita em fórmulas matemáticas que cabe à ciência descobrir, Newton passa a apreender o movimento a partir de axiomas... o pensamento moderno funda-se sobretudo na matemática. Desde então, a experiência que temos das coisas, da natureza já não é mais a mesma porque elas não se oferecem mais tão imediatamente aos nossos sentidos: elas passam a se referir ao que está prescrito num projeto que "determina também a maneira de acother e de recolher o que se mostra, a experiência" ${ }^{(12)}$. A experiência torna-se, então, experimentação e é a natureza que passa, com a ciência moderna, a ter de responder de tal ou de tal maneira ao projeto que previamente lhe colocamos.

No âmago desse projeto moderno de apreensão das coisas, tenta-se criar uma

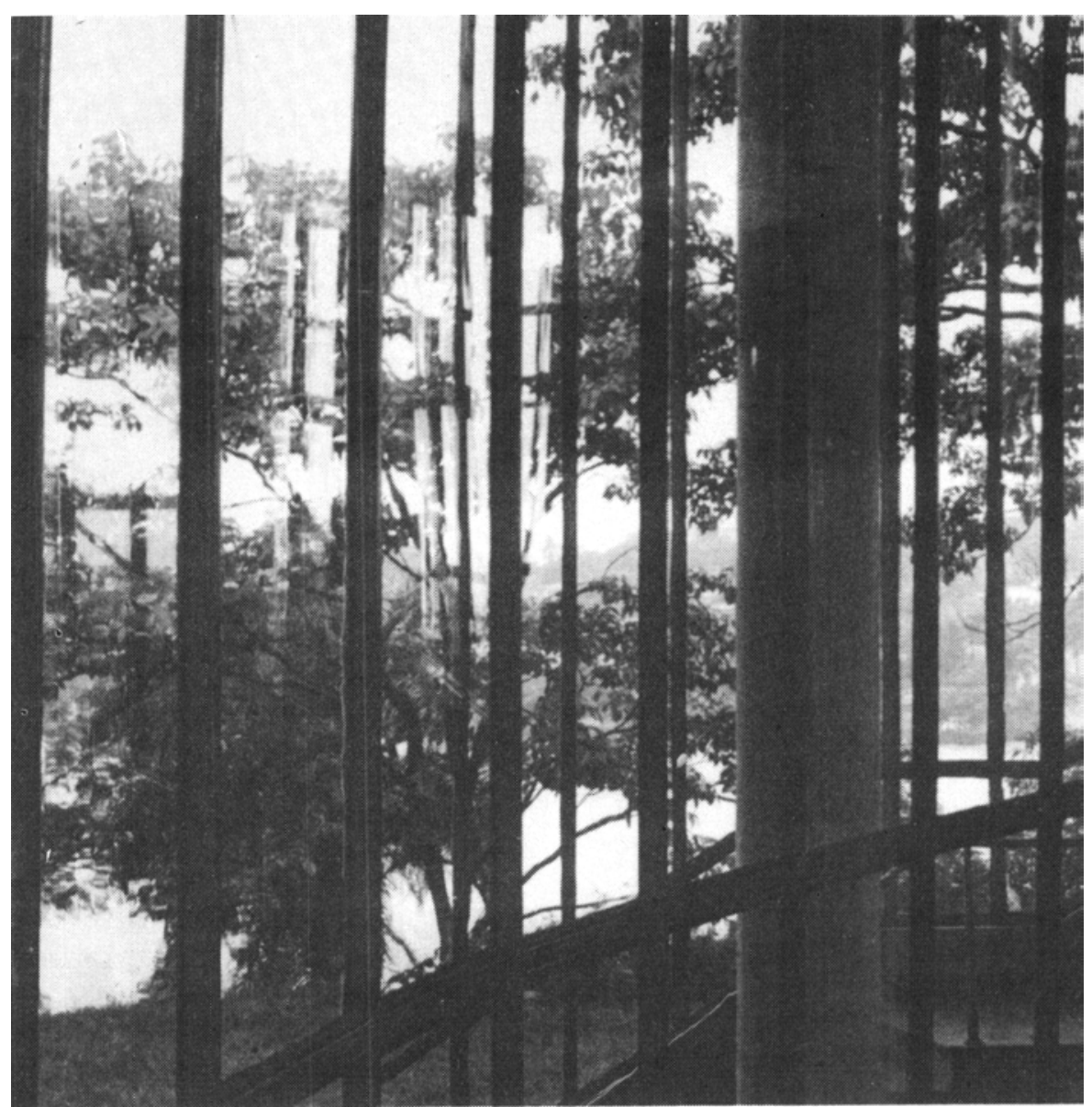

nova forma de saber que se funde sobre si mesma: "aí onde se aventura o aremesso do projeto matemático, o lançador desse projeto se estabelece sobre um solo que é, antes de tudo, fonte do projeto" (13). Para Heidegger, temos assim tanto a liberação de uma nova experiência, quanto a configuração de uma nova liberdade. Uma vez que a reflexão ética sempre nos conduz a uma reflexão sobre a liberdade, me parece possível aproximar essa posição de Heidegger com a passagem de Lacan citada no início deste artigo. Essa passagem nos ensinava que à medida em que a ciência avança, a ética é retificada. É exatamente isso que temos no século IV a.C.: se não encontramos nas escolas gregas desse período uma única concepção do que é a ética, é porque o conhecimento que elas produziram a propósito do mundo, da natureza, dos homens não é o mesmo ${ }^{(14)}$. É exatamente a isso, mas num contexto bem diferente, que Sade não se furta: a mudança que a ciência moderna opera na nossa concepção de natureza implica numa retificação da ética.

Tanto a obra como a vida de Sade nos mostram o quanto ele se interessava pela ciência de seu tempo: como um enciclopedista, ele catalogou pacientemente as mais variadas e múltiplas perversões, como um cientista ele teria querido testar um unguento que inventara na pela de uma de suas vítimas ${ }^{(15)} \ldots$ Sade vem nos falar de que existe uma satisfação no pior e uma "felicidade no mal", num mais além do prazer... Se ele pôde fazer disso uma posição ética, foi também fundado numa analogia com a natureza, entretanto a natureza sadeana não é a mesma daquela dos gregos. Trata-se de uma natureza em constante transformação, uma natureza que justifica o crime porque seria ela mesma criminosa:

\begin{abstract}
"O assassinato não é de modo algum umadestruiçäo; aquele que o comete apenas varia as formas (da natureza); ... como as criaçõessópodemser gozo paraaquele que se livra delas, o assassino... fornece (a natureza) materiais que ela emprega (...). A crueldade, longe de ser um vício, éo primeiro sentimento que a natureza imprime em nós. A criança quebra seu brinquedinho, morde a teta de sua ama de leite, estrangula seu pássaro..." (16).
\end{abstract}




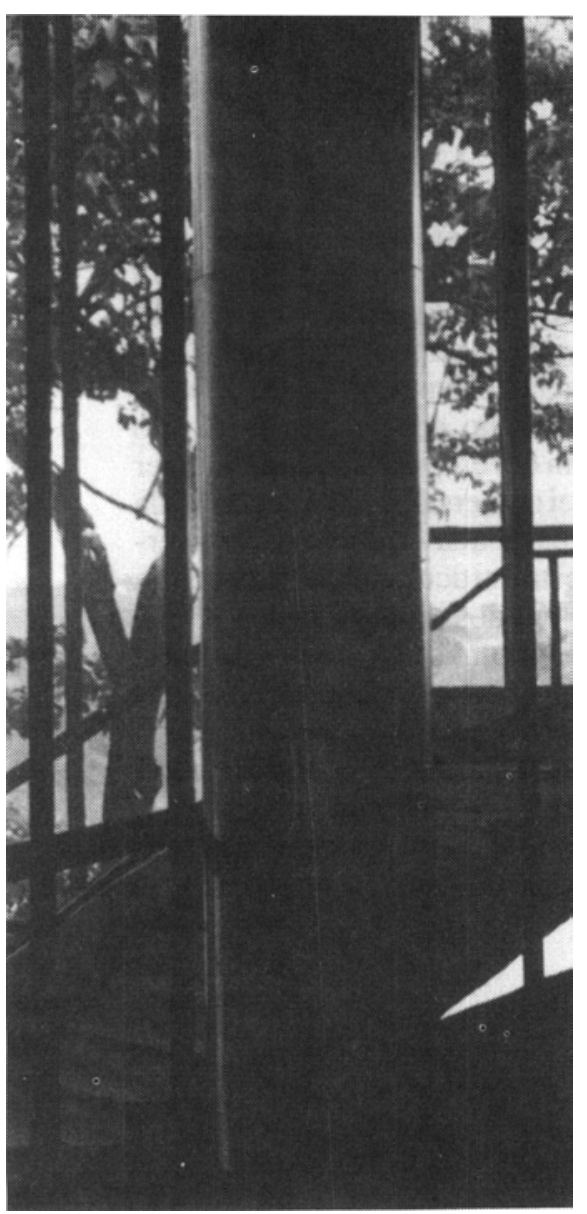

Explicitar porque o texto sadeano pode ser lido de um ponto de vista ético e não como uma aberração seria ultrapassar os limites deste artigo ${ }^{(17) .} \mathrm{O}$ que me interessa destacar em Sade é que uma mudança na concepção de natureza implica, para ele, numa transformação da visão habitual que se tem dos costumes, da vida, da morte, do desejo, da felicidade, da liberdade e mesmo da ética. Uma vez que o termo "ética" guarda em sua etimologia o sentido de morada que nos acolhe, podemos afirmar que a partir de Sade - como também desde Kant, mas num outro viés - habitar essa morada, ser ético são atos que ressaltam em nós uma tensão entre o que SOMOS e o que DEVEMOS SER, uma tensão a tal ponto incessante que, desde então, podemos ter esperança de que ela se resolva, mas jamais a certeza. Com a modemidade, 0 acolhimento que a ética nos oferece parece não ser dos mais hospitaleiros...

Tendo esclarecido então a citação inicial que fiz de Lacan, gostaria de pensá-la agora tendo em vista não apenas a ética, mas também a Psicologia e a Psicanálise. Psicologia e Psicanálise são tributárias dessa nova concepção de natureza que a ciência moderna nos legou. Wundt e Freud quiseram inscrever suas descobertas no campo da "ciên- cia da natureza", mas não podemos concluir daí que eles fizeram isso do mesmo modo. Essa diferença, a meu ver, marca definitivamente a distância entre a Psicologia e a Psicanálise, bem como as possibilidades de sustentarmos a existência de uma "ética da Psicologia"e de uma "ética da Psicanálise".

Wundt vai buscar em ciências já constituídas de seu tempo - a Física, a Fisiologia, por exemplo - o rigor e o método para fundamentar a Psicologia. Grande parte da história da Psicologia de William James aos modernos skinnerianos e à psicologia da "Nova Era" preconizada pela transpessoal - acaba por repetir, com mais ou menos sucesso, o procedimento wundtiano. Uma exceção podemos encontrar, talvez, no que se designa vagamente pelo nome de "psicologia humanista": é que os psicólogos humanistas pretendem, se afastandodo "passado" mecanicista da Psicologia, pensar esta última em sua particularidade enquanto "ciência humana"... no entanto, mesmo aí, a preocupação de um Carl Rogers em verificar suas proposições através de dispositivos como os "grupos de controle" acaba por reaproximar a "psicologia humanista" do procedimento que viria marcar a fundação da Psicologia como uma ciência.

Bem diversa foi a estratégia de Freud. Até no seu próprio nome - psic-análise o que Freud desenvolveu revela a marca das "ciências da natureza" (neste caso, a referência é a Química) e, ao longo de sua obra, são inúmeras as passagens onde Freud evoca os métodos de investigação e/ou as próprias descobertas da Física, da Biologia, da Química para justificar o modo como ele analisa suas descobertas clínicas, levanta hipótesese teoriza. Entretanto, a maneira como a Psicanálise se relacionou com as "ciências da natureza" ou, mais ainda, o modo como Freud a situou como sendo uma delas é totalmente diferente do que a Psicologia fez (e ainda faz) nesse sentido. É que por mais que todo o esforço de Freud tenha sido o de fazer da Psicanálise uma "ciência da natureza", seu trabalho jamais se colocou à sombra, numa subserviência ou numa rebeldia em relação às ciências que já estavam constituídas no seu tempo. Mais ainda, poderíamos dizer, Freud faz avançar essas ciências quando nos fala de uma "realidade psíquica" construída conforme nosso desejo, quando demonstra que "originariamente o eu inclui tudo" $\mathrm{e}$ que apenas "posteriormente separa, de si mesmo, um mundo externo" (18), quando explicita que sobre o instinto (que tem sempre um objeto definido) se apóia algo que lhe extrapola, a saber, a pulsão (que tem o objeto como seu elemento mais variável) e, por isso, mesmo bem alimentados, podemos ter vontade de comer mais, de comer algo que não sabemos o quê... mesmo excitados sexualmente e tendo como nos satisfazer de modo imediato, podemos preferir os jogos de sedução... mesmo insatisfeitos, há sempre algo em nós que se satisfaz... Freud faz avançar a ciência porque sua investigação subverte completamente as concepções que tínhamos de "natureza", "realidade", "sexualidade", "sujeito", "inconsciente" etc.

A perspectiva aberta por Freud é radicalmente diferente daquela que a Psicologia nos oferece. Como nos mostra Foucault em sua magistral arqueologia das ciências humanas, essas ciências (eentre elas estáa Psicologia) não podem ser ciências porque o que as possibilitam é uma relação de vizinhança (e mesmo de submissão) que elas mantêm com a Matemática, as Ciências Empíricas e a Filosofia e não um avanço quanto a uma certa concepção das coisas, do mundo e mesmo do tão falado "homem":

"O que explica a dificuldade das
ciências humanas, sua preca-
riedade, sua incerteza como ciên-
cias, sua perigosa familiaridade
com a filosofia, seu apoio mal
definido sobre outros dominios
do saber, seu caráter sempre
secundário ederivado, comotam-
bém sua pretensão ao universal,
não é, como frequentemente se
diz, a extrema densidade de seu
objeto; não é o estatuto metafísi-
coou aindestrutível transcendên-
cia desse homem de que elas
falam, mas antes a complexidade
da configuração epistemológica
onde se acham colocadas..." (19).

"O que explica a dificuldade das ciências humanas, sua precariedade, sua incerteza como ciências, sua perigosa familiaridade com a filosofia, seu apoio mal definido sobre outros dominios do saber, seu caráter sempre secundário e derivado, como também sua pretensão ao universal, não é, como frequentemente se diz, a extrema densidade de seu objeto; não é o estatuto metafisicoouaindestrutivel transcendência desse homem de que elas falam, mas antes a complexidade onde se acham colocadas..." (19). 
Outro percurso foi aquele de Freud. Assim, enquanto as ciências humanas "só se dirigem ao inconsciente virandolhe as costas, esperando que ele se desvele à medida em que se faz, como que por recuos, a análise da consciência"(20), enquanto a Psicologia lê o inconsciente apenas como um adjetivo ou um "outro nível da consciência", a Psicanálise faz dele um sistema que tem suas próprias leis, a Psicanálise "aponta diretamente para ele, de propósito deliberado - não em direção ao que deve explicitar-se pouco a pouco na iluminação progressiva do implícito, mas em direção ao que está aí e se furta, que existe com a solidez muda de uma coisa, de um texto fechado sobre si mesmo, ou de uma lacuna branca num texto visivel e que assim se defende"(2t). Nesse contexto, enquanto a Psicologia fica prisioneira do universo das representações e é condenada então a vagar indefinidamente em busca dos contornos dessa figura vaga e precária (a saber, o homem) que ela designa como seu objeto, a Psicanálise ultrapassa esse universo e funda um campo que lhe é próprio:

“... essa travessia só pode ser feita no interior de uma prática onde não é apenas o conhecimento que se tem do homem que está empenhado, masoprópriohomem - o homem com essa Morte que age no seu sofrimento, com esse Desejo que perdeu seu objeto e essalinguagempelaqual, através da qual se articula silenciosamente sua Lei.Todosaber analiticoé,pois, invencivelmente ligado a uma prática, a este estrangulamento da relação entre dois individuos, em que um escuta a linguagem do outro, libertando assim seu desejo do objeto que ele perdeu (fazendo-o entender que o perdeu) e libertando-o da vizinhança sempre repetida da morte (fazendo-o entender que um dia morrerá). É por isso que [ao contrário do que ocorre na psicologia] nada é mais estranho d psicanálise que alguma coisa como uma teoria geral do homem ou uma antropologia" (22).
Esses diferentes percursos da Psicologia e da Psicanálise no âmbito da ciência implicam também, a meu ver, perspectivas diferentes quanto à ética. Assim, o 'Código de Ética dos Psicólogos" é muito mais um conjunto de normas, de direitos e de deveres que regulam a profissão do psicólogo, ou seja, é muito mais algo que se inscreve no âmbito da legalidade do que no âmbito da ética. Não é gratuito, então, que as discussões nas "Comissões de Etica", que as análises e os juizos que tais comissões fazem a propósito dos processos que lhes são encaminhados não passam, muitas vezes, de leituras juridicas sobre a ação do psicólogo. $O$ recuo da Psicologia quanto à ciência parece se redobrar no que se refere à ética. $O$ que podemos ler no "Código de Ética dos Psicólogos" é um conjunto de permissões e interdições, uma restrição da ação do psicólogo que the é dada de fora (pelo próprio Código, pelo Conselho Federal de Psicologia, pelo Conselho Regional...), enquanto que aética, como já nos ensinou Kant, se refere a deveres que não são propriamente deveres estritos, prescrições que chegam para nós do exterior, mas sim a "deveres largos" que, ao contrário de restringir nossas possibilidades, nos permitem efetivar nossa liberdade, liberdade que conhecemos, segundo ele, a partir de uma lei que trazemos sempre dentro de nós ${ }^{(23)}$.

Ora, quando Lacan nos propõe uma ética da Psicanálise, não é sobre proibiçð̄es, restriçð̃es e/ou permissões que ele a estabelece. Essa ética sem dúvida, presentifica odevere o direito, mas estes

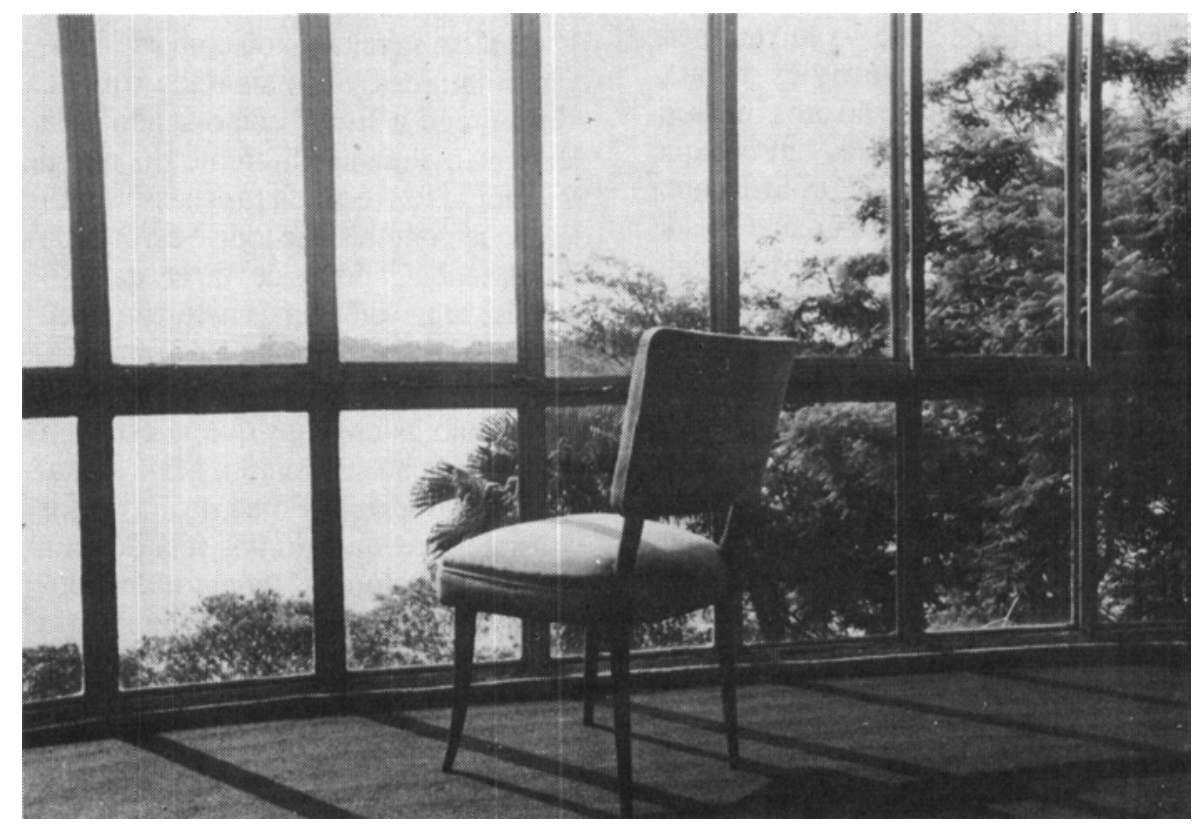

não são representáveis como acontece no caso do código de ética que rege a prática dos psicólogos. A ética da Psicanálise jamais comportaria um código porque nela a orientação da ação humana se funda no desejo (Lacan faz do desejo um dever) que "não tem o caráter de uma lei universal, mas ao contrário da lei mais particular - mesmo se é universal que esta particularidade se encontra em cada um dos seres humanos" (24). A ética da Psicanálise jamais comportaria um código porque nela o direito concerne ao gozo, gozo que - mesmo podendo ser restringido pelo imperativo moral do supereu - transborda sempre para além dos limites da lei e da representação ${ }^{(25)}$. 
(1)LACAN,J.Kantavec Sade (1962). Ecrits. Paris, Seuil, 1966: 765.

(2) LIMA VAZ, H.C. Escritos de filosofia II: ética e cultura. São Paulo, Loyola, 1988: 11.

(3) Ibidem. 14.

(4 Ver: JAEGER, W. Paidéia: a formação do homem grego. Sāo Paulo, Martins Fontes, 1989: 335 e ss.

(5) LIMA VAZ, H.C. Op. cit. 11-16, 148-161, 197.

(6) JAEGER, W. Op. cit. 335 .

(7) Ibidem. 335.

(8) Encontrei essa citação de Eveno em Aristóteles. Ver: ARISTÓTELES. L'éthique às Nicomaque. Tomo $I, 2^{\circ}$ parte. Louvain/Paris, Publications Universitaires/Béatrice-Nawelaerts, 1970 : 207.

(9)Ver:FOUCAULT, M. Histoire de la sexualité: l' usage des plaisirs. Vol.II. Paris, Gallimard, 1984.

(10) Ver: BROCHARD, V.Lamorale ancienne et la morale moderne. Bevue Philosophique de la France et de l'Etranger. Tomo LI, (1901): 01-12.

(11) GOFF, J. A bolsa e a vida; economia e religiano na Idade Média (1986). Sāo Paulo, Brasiliense, 1989: 25.

(12)HEIDEGGER, Qu'est ce qu'une chose? (1962). Paris, Gallimard, 1971 . 104.

(13) Ibidem. 107.

(14) Para uma leitura mais detalhada sobre essas diferenças entre as escolas de filosofia grega no que diz respeito à ética, ver: LEBRUN, G. A neutralizaçäo do prazer. In: NOVAES, A. (org.). $O$ desejo. São Paulo, Companhia das Letras, 1990: 67-69.

(15) Ver obras de Sade como Os cento e vinte dias de Sodoma e a recente e bem documentada biografia de Sade escrita magnificamente por Pauvgert: SADE. Oeuvres completes. Tomo I. Pa- ris, Pauvert, 1986: 19-451; PAUVERT.J. J. Sade vivant. Vols. I, II III. Paris, Rober Laffont, 1986, 1989, 1991.

(16) SADE. La philosophie dans le boudoir (1795). Paris, Gallimard, 1976: 108, 129.

(17) Um outro artigo que escrevi desenvolve mais essa questão. Ver: LAIA, S. A ética, seus paradoxos e suas patologias. Correio do Simpósio. N 05 (1989): 20-22.

(18) FREUD, S. O mal-estar na civilizaçāo (1929). Obras completas. Vol. XXI. Rio de Janeiro, Imago, 1976: 85.

(19) FOUCAULT, M. As palavras e as coisas (1964). São Paulo, Martins Fontes, 1987: 365 .

(20) Ibidem. 391 .

(21) Ibidem. 391.

(22) Ibidem. 393.

(23) Para Kant, nāo é funçāo da ética representar especifica e restritamente o que é nosso dever. Por isso, desde a Crítica da razão prática a lei fundamental da razāo pura prática nos é dada através de um imperativo que explicita como devemos agir bem do ponto de vista moral, mas esse imperativo não nos oferece qualquer exemplo de ação moral; ele é ao mesmo tempo rigoroso, formal e amplo: "aja de tal modo que a máxima de tua vontade possa sempre valer ao mesmo tempo como princípio de uma legislaçāo universal". Ver: KANT, $I$. Critique de la raison pratique (1788). $\mathrm{Pa}$ ris, Quadriage/PUF, 1985: 30. Numa obra mais tardia, que contémefetivamente a ética de Kant (a Crítica da razão prática apenas the serve de fundamento), essa exigência de que o campo ético seja ao mesmo tempo formal, rigoroso $e$ aberto torna-se ainda mais evidente: na Metafisica dos costumes, Kant nos ensina que o direito é um ramo da ética, mas näo se confunde com ela porque - no que concerne à ética - à restrição que caracteriza os deveres de direito deve-se acrescentar um princípio aberto. $\mathrm{Na} D O U$ TRINA DO DIREITO, "deixa-se a cada um a liberdade de fixar para as suas açōes ofim que the convém", mas a máxima dessas açōes "é determinada a priori: é necessário que a liberdade do agente possa concordar com a liberdade de qualquer outro, segundo uma lei universal". A ETICA, ao contrário, implica um outro percurso: "ela só pode partir de fins que o homem pode se propor e decidir, assim, as máximas que ele deve admitir, isto é, segundo seu dever", um dever que, enraizado na razāo pura não se confunde com princípios empíricose sensíveis. Por isso, "na ética será.. o CONCEITO DEDEVER que conduzirá aos fins e as MÁXIMAS relativas cos fins que DEVEMOS nos propor deveräo se fundar sobre princípios morais". Ver: KANT I. Métaphysique des moeurs. Segunda parte. Paris, Vrin, 1985: 52-53. Desse modo, para Kant, éna ausência de toda coação externa (mas napresença de uma coaçāo interna exercidapelaprópria consciência da lei moral em nós) que agimos eticamente.

(24) LACAN, J. Le seminaire: l'éthique de la psychanalyse (1959/60). Livro VII. Paris, Seuil, 1986: 33. E importante ressaltar que a noçāo de desejo que encontramos em Freud e em Lacan nāo se confunde de modo algum com uma simples volição $e$, portanto, que a ética da psicanálise - ao fazer do desejo um dever - näo incorre em qualquer voluntarismo do tipo "é assim, porque eu quero...", "não é desse jeito porque é contrário ao meu desejo...". No seminário consagradoà ética dapsicanálise, Lacan faz um longo comentário a propósito de Antigona onde se evidencia o caráter trágico do desejo humano, essa visāo do desejo que nos coloca além do princípio do prazer e que nos afasta de toda concepção habitual que temos da felicidade.

(25) Para ilustrar a relaçāo do direito como gozo, Lacan nos lembra a noçāo jurídica do "usufruto "que implica que podemos gozar de certos bens desde que tenhamos cuidado, desde que não abusemos... A essência do direito é, segundo Lacan, "repetir, distribuir, retribuir o que é da ordem do gozo". Ver: LACAN, J. Le séminaire: encore. (1972-1973). Livro XX. Paris, Seuil, 1975:9-17. Ora, as exigências do supereu, da "consciência moral" implicam justamente essa repartição e essa retribuição do que se refere ao gozo. Entretanto, a clínica psicanalítica nos mostra também que nem todo gozo é assim täo compartilhável, tão circulável: há certos gozos que tomam o corpo do analisando de tal modo que ele (quase) nāo os profere... 